\title{
The effects of bariatric surgical procedures on the improvement of metabolic syndrome in morbidly obese patients: Comparison of laparoscopic sleeve gastrectomy versus laparoscopic Roux-en-Y gastric bypass
}

\author{
Mehmet Ertuğrul Kafalı, Mustafa Şahin, IIlhan Ece, Fahrettin Acar, Hüseyin Yılmaz, Hüsnü Alptekin, Leyla Ateș
}

\section{ABSTRACT}

Cite this paper as: Kafalı ME, Şahin M, Ece I, Acar F, YlImaz H, Alptekin $H$, Ateş L. The effects of bariatric surgical procedures on the improvement of metabolic syndrome in morbidly obese patients: Comparison of laparoscopic sleeve gastrectomy versus laparoscopic Roux-en-Y gastric bypass. Turk J Surg 2017; 33: 142-146.

Department of General Surgery, Selcuk University School of Medicine, Konya, Turkey

Address for Correspondence illhan Ece

e-mail: ihanece@yahoo.com

Received: 13.03.2017

Accepted: 12.05.2017

(C) Copyright 2017

by Turkish Surgical Association
Objective: The objective of this study was to evaluate patients who underwent laparoscopic Roux-en-Y gastric bypass and laparoscopic sleeve gastrectomy in terms of weight loss, metabolic parameters, and postoperative complications.

Material and Methods: Data on patients who underwent laparoscopic Roux-en-Y gastric bypass and laparoscopic sleeve gastrectomy with a diagnosis of morbid obesity between January 2012 and June 2014 were retrospectively evaluated. Patients were compared in terms of age, sex, body mass index, duration of operation, American Society of Anesthesiologists score, perioperative complications, length of hospital stay, and long term follow-up results.

Results: During the study period, 91 patients (45 laparoscopic Roux-en-Y gastric bypass and 46 laparoscopic sleeve gastrectomy) underwent bariatric surgery. There was no difference between the two groups in terms of preoperative patient characteristics. Both groups showed statistically significant weight loss and improvement in co-morbidities when compared with the preoperative period. Weight loss and improvement in metabolic parameters were similar in both groups. The duration of operation and hospital stay was longer in the laparoscopic Roux-en-Y gastric bypass group. Furthermore, the rate of total complications was significantly lower in the laparoscopic sleeve gastrectomy group.

Conclusion: Laparoscopic sleeve gastrectomy is a safe and effective method with a significantly lower complication rate and length of hospital stay than laparoscopic Roux-en-Y gastric bypass, with similar improvement rates in metabolic syndrome.

Keywords: Morbid obesity, weight loss, metabolic syndrome, surgical complication

\section{INTRODUCTION}

Obesity is defined as a body weight $20 \%$ greater than the expected weight or a body mass index (BMI) greater than $30 \mathrm{~kg} / \mathrm{m}^{2}$, and is a rapidly spreading public health problem throughout the world (1). BMI over $35 \mathrm{~kg} / \mathrm{m}^{2}$ with severe comorbidities or BMI above $40 \mathrm{~kg} / \mathrm{m}^{2}$ without complaints is classified as morbid obesity. Dietary and lifestyle changes are inadequate treatment methods in morbid obesity in terms of long-term weight loss (2). Thus, surgery is the only effective treatment of morbid obesity $(3,4)$. Laparoscopic Roux-en-Y gastric bypass (LRYGB) and laparoscopic sleeve gastrectomy (LSG) are the most commonly used methods for surgical treatment. LRYGB is a safe technique that has been applied for many years due to its mal-absorptive effect in addition to its volume-limiting effect (5). The most important disadvantage of this surgical technique is postoperative nutritional deficiencies that require longterm follow-up (6). Since LSG is easy to learn, has fewer complication rates, and has fewer nutritional effects, it is being increasingly used in the surgical treatment of obesity $(7,8)$.

The increase in body mass index is associated with metabolic diseases such as glucose intolerance, diabetes, dyslipidemia, hypertension and coronary artery disease. The association of obesity and metabolic diseases is called metabolic syndrome (9). In this study, we aimed to compare the effects of two different surgical techniques used for obesity treatment on obesity and metabolic syndrome.

\section{MATERIAL AND METHODS}

The data on patients with BMI over $40 \mathrm{~kg} / \mathrm{m}^{2}$ or BMI between 35 and $40 \mathrm{~kg} / \mathrm{m}^{2}$ with serious comorbidities according to the International Federation for the Surgery of Obesity (IFSO) criterion who have been treated by LSG and LRYGB at the Selçuk University Research Hospital, Obesity and Metabolic Surgery Clinic between January 2012 and June 2014 were retrospectively reviewed. The study was conducted in accordance with ethical standards set in the Helsinki Declaration with the approval of the local ethics committee. Patient informed consent was not obtained due to the retrospective nature of the study. However, prior to the operation, the patients were informed about the possible complications of the surgical procedures and informed consents were obtained. The surgical technique to be applied was decided according to patient BMI, co-morbid diseases and patient preference. Patient age, gender, BMI, duration of operation, American Society of Anesthesiologists (ASA) score, perioperative complications, length of hospital stay, and long-term follow-up results were obtained from hospital records. Patients 
with ASA score IV or higher, and those with a history of previous anti-reflux or gastric surgery were excluded from the study.

All patients were assessed for cardiac, pulmonary and endocrinology risk of surgery and anesthesia. Abdominal ultrasound and upper gastrointestinal endoscopy was routinely performed. LRYGB was preferred in patients with evidence of esophagitis on endoscopy. All patients underwent a standard diet protocol in the postoperative period, with liquid diet in the first 1 month and soft diet in the second and third months. After the third month, patients were allowed a normal diet. Vitamin supplements were not prescribed routinely for patients with LSG, they were recommended individually according to postoperative follow-up results. Patients receiving LRYGB were routinely discharged with multivitamin supplements.

Patients were regularly monitored by a member of the surgical team and a dietitian. The first postoperative follow-up was performed at the end of the first week. Subsequent follow-ups were set at 1, 2, 3, 6, 12 and 24 months. Patient medication, $\mathrm{BMI}$, excess weight loss, glucose, HbA1c, cholesterol, blood pressure were recorded.

\section{Surgical Technique}

All patients received antibiotic prophylaxis (Cephazolin $2 \mathrm{~g} \mathrm{IV}$ ), and thromboemboli prophylaxis with low molecular weight heparin (Enoxaparin 6000 anti-Xa IU 60 mg) and intermittent pneumatic compression stockings and were operated in the semi-lithotomy position.

The standard 4 port technique was used for LSG. The first port was placed in the abdomen supra-umbilically and $\mathrm{CO}_{2}$ insufflation was established at a pressure of $12 \mathrm{mmHg}$. A 5 $\mathrm{mm}$ port was placed for liver retraction from the subxiphoid area. The working ports were placed under direct vision from the right and left subcostal lines. Gastric vascular structures on the greater curvature were mobilized by using a vascular sealing device (Ligasure; Maryland, Covidien, CO, USA). The stomach was divided starting $2 \mathrm{~cm}$ from the pylorus until 1 $\mathrm{cm}$ to the angle of His vertically over a $36 \mathrm{Fr}$ calibration tube by using 4-to-6 60-mm staplers (Covidien; Endo-GIATM, TriStapleTM, USA). In all patients, the stapler line was sutured with a running suture (V-Loc; Covidien, USA) to prevent bleeding and a silicone drain was placed along the suture line.

Laparoscopic Roux-en-Y gastric bypass was performed with the 7 port technique. The stomach was divided by using 2-3 laparoscopic staplers from the lesser curvature to the angle of His after mobilization of the lesser omentum so as to prepare a gastric pouch of $20-30 \mathrm{~mL}$ volume. The jejunum was divided as the alimentary limb would be $150 \mathrm{~cm}$ from the Treitz ligament and the biliary limb would be $60 \mathrm{~cm}$. The greater omentum was routinely separated from the transverse colon to prevent tension in the gastrojejunostomy anastomosis. All patients underwent gastrojejunostomy with Orvil ${ }^{\mathrm{TM}}$ (Covidien; Autosuture, Mansfield, MA, USA) and $25 \mathrm{~mm}$ circular staplers, which were introduced into the stomach orally. The jejunojejunostomy anastomosis was performed with a laparoscopic linear stapler. One soft drain was placed in proximity to the gastrojejunostomy line.

\section{Statistical Analysis}

Data were collected by using Microsoft Excel 2007 (Microsoft, Redmond, WA, USA) and statistical analyzes were performed by using Statistical Package for the Social Sciences 16.0 (SPSS Inc.; Chicago, IL, USA). Student's t test and chi-square test were used to analyze demographic data. Non-parametric tests were used since the majority of the variables in normal distribution controls were identified to be not normally distributed. Independent two group comparisons were made by Mann-Whitney test, and Wilcoxon test was used for dependent group comparison in each group. Categorical variables were expressed as percentage and continuous variables as mean \pm standard deviation. $P$ value $<0.05$ was considered as significant.

\section{RESULTS}

A total of 91 patients, 24 male and 67 female, who underwent obesity surgery in our clinic and met the inclusion criteria were included in the study. LRYGB was performed on 45 of the 91 patients and LSG was performed on the remaining 46 patients. Preoperative characteristics of the patients are outlined in Table 1. The operative time in the LRYGB group was statistically significantly high. Also, the patients in the LRYGB group had longer hospital stay. Preoperative BMI was significantly higher in the LRGB group than that of the LSG group. When patients were assessed in terms of comorbid diseases; patients in the LRYGB group were found to have more comorbidities, although not statistically significant. Patients were followed-up for at least 24 months in both groups. The 24-month BMIs were similar in both groups. The initial BMI was higher in the LRYGB group; therefore, excess weight loss was found to be lower in the LSG group. However, this difference was not statistically significant. When patients with metabolic syndrome were compared in both groups; the decrease in fasting blood glucose, cholesterol, and $\mathrm{HbA1c}$ levels were similar (Table 2). The mean preoperative insulin dose used by insulin-dependent diabetic patients was 52.71 \pm 20.1 units/ day in the LSG group, and $55.47 \pm 23.3$ units/day in the LRYGB group (Table 3,4 ). At the $12^{\text {th }}$ month postoperative follow-up, daily insulin doses were decreased down to $12.1 \pm 9.1$ units in the LSG group, and $8.9 \pm 7.3$ units in the LRYGB group. At the end of the second year, there were no patients in both groups who required insulin treatment. Oral anti-diabetic medication was required in 1 (2.2\%) patient in the LRYGB group, and in 2 (4.3\%) patients in the LSG group due to partial remission in diabetes mellitus. When the groups were compared in terms of cholesterol levels, the preoperative levels and the decrease rate of cholesterol levels at 24 months were similar. There were no mortalities during the study period. Complications of surgical groups are listed in Table 5. One patient underwent an endoscopic expandable stent replacement due to a stapler line leakage in the LSG group. The stent was removed at 4 weeks after endoscopic and radiological confirmation of leak closure. Another patient in the LSG group developed postoperative bleeding that was controlled by conservative methods. Surgical site infection of the port site where the stomach has been extracted was treated with drainage and oral antibiotics in 3 patients. In the LRYGB group, 2 patients were treated for postoperative bleeding, 4 for surgical site infection, and 3 for anastomotic leak. All bleedings were controlled by blood transfusion and did not require re-operation. Anastomotic leak in the gastrojejunostomy anastomosis was successfully closed with 
deficiencies that may occur in the postoperative period (10). Rapid transfer of stomach contents to the ileum after LRGB is associated with induction of incretins that increase insulin secretion and thus control of blood glucose levels (11). It is known that LSG reduces gastric transit time and as a result it provides early contact of gastric content with the ileum (12). Several studies comparing LSG and LRYGB in terms of type 2 diabetes remission rate showed that the positive effect of LRYGB on glucose metabolism is superior to that of LSG due to its mal-absorptive component (13). However, there is no consensus on this topic in the literature. There are studies advocating that both techniques have no significant superiority over each other in terms of blood glucose and $\mathrm{HbA} 1 \mathrm{c} \mathrm{lev-}$ els (14). According to the results of our study, LRYGB was not found to have a statistically significant superiority over LSG in terms of diabetes remission rate. We believe that by providing similar excess weight loss both techniques resulted in elimination of insulin resistance and thus led to comparable results in diabetes remission rate. In addition, elimination of the gastric fundus, which plays an important role in the secretion of ghrelin hormone, in both surgical techniques can provide adequate appetite reduction in patients (15). The gastric fundus is not resected in the LRYGB technique. However, the study by Sundbom et al. (16) showed that vagal denervation of the gastric fundus significantly reduced circulating ghrelin levels. As a result, it is known that any bariatric operation that reduces circulating ghrelin levels provides effective weight loss in the early period (15).

Laparoscopic sleeve gastrectomy has become the most common bariatric surgical method worldwide because of its low complication rate, short learning curve and ease of application (17-19). The most important complications of LSG are hemorrhage and stapler line leakage. Although stapler line leaks are reported at very low rates $(0.74-1.7 \%)$, they have high clinical significance and may result in prolonged hospitalization, increased morbidity, sepsis, multi-organ failure and death (20-22). In the meta-analysis performed by Rausa et al. (23) the reoperation rate after LRYGB was found to be $1.4-3.1 \%$. In addition, serious complications of LRYGB include bleeding $(1.4 \%)$, anastomotic stricture (1.4\%), infection (1.0\%), fistula $(0.5 \%)$, internal hernia (1.1\%), and port site hernia (1.0\%) (24).

When the long term results of both techniques are examined, it is reported that LRYGB is superior to LSG in terms of weight loss and resolution of comorbidities. However, LSG can achieve acceptable weight loss with sufficient improvement in comorbidities at 5-year follow-up (25). It is also possible to apply a re-sleeve or gastric bypass technique if patients develop symptoms of weight gain or gastro-esophageal reflux, since they will have a lower body weight than their initial weight.

\section{CONCLUSION}

Laparoscopic sleeve gastrectomy, which is prefersred in obesity surgery with its volume-limiting effect, is a safe and effective method that can be applied with less complication rates in comparison to LRYGB along with comparable results in the treatment of obesity related metabolic syndrome.

Ethics Committee Approval: Authors declared that the research was conducted according to the principles of the World Medical Associa- tion Declaration of Helsinki "Ethical Principles for Medical Research Involving Human Subjects" (amended in October 2013).

Informed Consent: Informed consent was not received due to the retrospective nature of the study.

Peer-review: Externally peer-reviewed.

Author Contributions: Concept - M.Ş.; Design - I.E.; Supervision - M.Ş.; Resource - M.E.K., L.A.; Materials - İ.E., M..E.K.; Data Collection and/or Processing - I.E., M..E.K., F.A. .; Analysis and/or Interpretation - M.E.K., I.E.; Literature Search - I.E., H.A, H.Y.; Writing Manuscript - M.Ş., I.E.; Critical Reviews - M.Ş.

Conflict of Interest: No conflict of interest was declared by the authors.

Financial Disclosure: The authors declared that this study has received no financial support.

\section{REFERENCES}

1. The National Institutes of Health Conference. Gastrointestinal surgery for severe obesity. Consensus development conference panel. Ann Intern Med 1991; 115: 956-961.

2. Miller WC, Koceja DM, Hamilton EJ. A meta-analysis of the past 25 years of weight loss research using diet, exercise or diet plus exercise intervention. Int J Obes Relat Metab Disord 1997; 21: 941-917. [CrossRef]

3. Buchwald $H$, Avidor $Y$, Braunwald $E$, Jensen MD, Pories W, Fahrbach $\mathrm{K}$, et al. Bariatric surgery: a systematic review and metaanalysis. JAMA 2004; 292: 1724-1737. [CrossRef]

4. Christou NV, Sampalis JS, Liberman M, Look D, Auger S, McLean $A P$, et al. Surgery decreases long-term mortality, morbidity, and health care use in morbidly obese patients. Ann Surg 2004; 240: 416-423. [CrossRef]

5. Kim S, Richards WO. Long-term follow-up of the metabolic profiles in obese patients with type 2 diabetes mellitus after Rouxen-Y gastric bypass. Ann Surg 2010; 251: 1049-1055. [CrossRef]

6. Dalcanale L, Oliveira CP, Faintuch J, Nogueira MA, Rondó P, Lima $\mathrm{VM}$, et al. Long-term nutritional outcome after gastric bypass. Obes Surg 2010; 20: 181-187. [CrossRef]

7. Zachariah SK, Chang P-C, Ooi ASE, Hsin M-C, Kin Wat JY, Huang CK. Laparoscopic sleeve gastrectomy for morbid obesity: 5 years experience from an Asian center of excellence. Obes Surg 2013; 23: 939-946. [CrossRef]

8. Fischer L, Hildebrandt C, Bruckner T, Kenngott H, Linke GR, Gehrig $T$, et al. Excessive weight loss after sleeve gastrectomy: a systematic review. Obes Surg 2012; 22: 721-731. [CrossRef]

9. Williams $S$, Cunningham E, Pories WJ. Surgical treatment of metabolic syndrome. Med Princ Pract 2012; 21: 301-309. [CrossRef]

10. Coupaye $M$, Rivière $P$, Breuil $M C$, Castel $B$, Bogard $C$, Dupré $T$, et al. Comparison of nutritional status during the first year after sleeve gastrectomy and Roux-en-Y gastric bypass. Obes Surg 2014; 24: 276-283. [CrossRef]

11. Rubino F, Forgione A, Cummings DE, Vix M, Gnuli D, Mingrone $\mathrm{G}$, et al. The mechanism of diabetes control after gastrointestinal bypass surgery reveals a role of the proximal small intestine in the pathophysiology of type 2 diabetes. Ann Surg 2006; 244: 741749. [CrossRef]

12. Nosso G, Griffo E, Cotugno M, Saldalamacchia G, Lupoli R, Pacini $G$, et al. Comparative effects of Roux-en- $Y$ gastric bypass and sleeve gastrectomy on glucose homeostasis and incretin hormones in obese type 2 diabetic patients: A one-year prospective study. Horm Metab Res 2016; 48: 312-317. [CrossRef]

13. Menguer RK, Weston AC, Schmid H. Evaluation of metabolic syndrome in morbidly obese patients submitted to laparoscopic bariatric surgery: Comparison of the results between Roux-en-Y 
gastric bypass and sleeve gastrectomy. Obes Surg 2017; 27: 17191723. [CrossRef]

14. Keidar A, Hershkop KJ, Marko L, Schweiger C, Hecht L, Bartov N, et al. Roux-en-Y gastric bypass vs sleeve gastrectomy for obese patients with type 2 diabetes: a randomised trial. Diabetologia 2013; 56: 1914-1918. [CrossRef]

15. Peterli R, Borbély $Y$, Kern B, Gass M, Peters T, Thurnheer $M$, et al. Early results of the Swiss Multicentre Bypass or Sleeve Study (SMBOSS): a prospective randomized trial comparing laparoscopic sleeve gastrectomy and Roux-en-Y gastric bypass. Ann Surg 2013; 258: 690-694. [CrossRef]

16. Sundbom M, Holdstock C, Engström BE, Karlsson FA. Early changes in ghrelin following Roux-en-Y gastric bypass: influence of vagal nerve functionality? Obes Surg 2007; 17: 304-310. [CrossRef]

17. Benaiges D, Más-Lorenzo A, Goday A, Ramon JM, Chillarón JJ, Pedro-Botet J, et al. Laparoscopic sleeve gastrectomy: more than a restrictive bariatric surgery procedure? World J Gastroenterol 2015; 21: 11804-11814. [CrossRef]

18. Shi X, Karmali S, Sharma AM, Birch DW. A review of laparoscopic sleeve gastrectomy for morbid obesity. Obes Surg 2010; 20: 1171-1177. [CrossRef]

19. Berger ER, Clements RH, Morton JM, Huffman KM, Wolfe BM, Nguyen NT, et al. The impact of different surgical techniques on outcomes in laparoscopic sleeve gastrectomies: the first report from the Metabolic and Bariatric Surgery Accreditation and Quality Improvement Program (MBSAQIP). Ann Surg 2016; 264: 464473. [CrossRef]
20. Benedix F, Poranzke O, Adolf D, Wolff S, Lippert H, Arend J, et al. Staple line leak after primary sleeve gastrectomy-risk factors and mid-term results: Do patients still benefit from the weight loss procedure? Obes Surg 2017; 27: 1780-1788. [CrossRef]

21. Gagner M, Deitel M, Erickson AL, Crosby RD. Survey on laparoscopic sleeve gastrectomy (LSG) at the Fourth International Consensus Summit on Sleeve Gastrectomy. Obes Surg 2013; 23: 2013-2017. [CrossRef]

22. Hutter MM, Schirmer BD, Jones DB, Ko CY, Cohen ME, Merkow RP, et al. First report from the American College of Surgeons Bariatric Surgery Center Network: laparoscopic sleeve gastrectomy has morbidity and effectiveness positioned between the band and the bypass. Ann Surg 2011; 254: 410-420. [CrossRef]

23. Rausa E, Bonavina L, Asti E, Gaeta M, Ricci C. Rate of death and complications in laparoscopic and open roux-en-y gastric bypass. A meta-analysis and meta-regression analysis on 69,494 patients. Obes Surg 2016; 26: 1956-1963. [CrossRef]

24. Abdeen G, le Roux CW. Mechanism underlying the weight loss and complications of Roux-en-Y gastric bypass. Obes Surg 2016; 26: 410-421. [CrossRef]

25. Angrisani L, Santonicola A, Hasani A, Nosso G, Capaldo B, lovino P. Five-year results of laparoscopic sleeve gastrectomy: effects on gastroesophageal reflux disease symptoms and co-morbidities. Surg Obes Relat Dis. 2016; 12: 960-968.[CrossRef] 